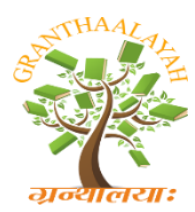

\author{
INTERNATIONAL JOURNAL OF RESEARCH - \\ GRANTHAALAYAH \\ A knowledge Repository
}

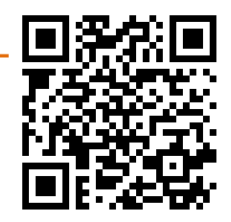

Science

\title{
A COMPREHENSSIVE REVIEW ON MANAGEMENT OF HEMORRHOIDS (GUDARSHA) - AN INTEGRATED APPROACH
}

\author{
Dwivedi Amarprakash *1, Pathrikar Anaya ${ }^{2}$, Amitabh Kumar ${ }^{3}$, Shukla Mukesh 4 \\ ${ }^{*}$ Professor, School of Ayurveda, D. Y. Patil University, Navi Mumbai, Maharashtra, India \\ ${ }^{2}$ Professor, Kayachikitsa, AVPM's Ayurved Mahavidyalaya, Sion, Mumbai, India \\ ${ }^{3}$ Ph.D. (Scholar), Mandsaur College of Ayurveda, Mandsaur, Madhya Pradesh, India \\ ${ }^{4}$ Professor, Panchkarma, KGMP Ayurved Mahavidyalaya, Mumbai, India
}

\begin{abstract}
Background-Haemorrhoid is a condition characterized by the prolapsed of an anal cushion that may result in bleeding and pain from rectum or anal canal. It is said to be the fourth leading outpatient gastrointestinal diagnosis. Modern medical science has treatment alternatives such as diet- lifestyle modification, sclerotherapy, banding, LASER ablation etc. in early stage and various surgical procedures such as Haemorrhoidectomy, MIPH etc. in advanced stage with varied prognosis. Haemorrhoid can be co-related with Gud-Arsha in Ayurveda. Ayurvedic texts suggest fourfold treatment for Arsha such as Bheshaj (Medicinal treatment), Kshar karma (Herbal caustic paste), Agnikarma (thermal heat burn) and Shastra karma (Surgery).

Method- In this review article, information from modern surgery texts in view of definition, aetiology, patho-physiology, sign and symptoms and available treatment options as per stage of disease and a gist of contemporary texts of Ayurveda related to Arsha (Haemorrhoid) have been documented to understand integrated and holistic treatment approach towards haemorrhoid management.

Result \& Conclusion- The article attempts to simplify haemorrhoid management and touches maximum aspects of this disease with an integrated approach. Hence, this article will certainly prove useful to proctologist and researchers belonging to field of Modern and Ayurveda, to know about holistic haemorrhoid management.
\end{abstract}

Keywords: Haemorrhoid; Sclerotherapy; Laser Ablation; Hemorrhoidectomy; Arsha Chikitsa.

Cite This Article: Dwivedi Amarprakash, Pathrikar Anaya, Amitabh Kumar, and Shukla Mukesh. (2019). "A COMPREHENSSIVE REVIEW ON MANAGEMENT OF HEMORRHOIDS (GUDARSHA) - AN INTEGRATED APPROACH.” International Journal of Research - Granthaalayah, 7(7), 310-320. https://doi.org/10.29121/granthaalayah.v7.i7.2019.769.

\section{Introduction}

In today's modernized world, shift duties, stressful life, eating of unhealthy foods makes people more prone to the ano-rectal diseases such as fissure and haemorrhoid. The dilation of the veins of 
the internal rectal plexus constitutes the condition of the internal haemorrhoids which are covered by the mucous membrane. ${ }^{[1]}$ Haemorrhoids are commonly occurring in the fourth to sixth decades, however may affect patients of all ages. In India, 1 million new cases are reported annually, 47 per 1000 and increases with age, and it is estimated that in the age group of 45-65 years, 50-85\% of people around the world have haemorrhoids. Also, males are more prone to develop haemorrhoids compare to females. Furthermore, due to site of disease, many of the patients hesitate to go to doctor and they delay the examination and treatment which ultimately leads to worsen condition of the disease. The modern medicine advocates various procedure such as sclero-therapy, rubber banding, DGHAL, LASER ablation, haemorrhoidectomy etc. with varied prognosis.

Traditional science of Ayurveda, explains haemorrhoids as Gud-Arsha and based on stage, four different treatment modalities have been advocated for Arsha. In early stage with less signs symptoms Arsha can be treated with Bheshaja (internal medicine), Ksharkarma (herbal caustic paste locally) or Agnikarma (thermal heat burn) and if not cured with all above treatment, it should be treated by Shastrakarma (Surgery). ${ }^{[2,3]}$

In this article aetiology, pathogenesis, clinical manifestation of haemorrhoid and various treatment alternatives from modern surgery and Ayurveda have been dealt in detail. Hence, the article will prove beneficial for surgeons and researchers working in the field of proctology.

\section{Methodology}

In this review article, information from modern surgery texts in view of definition, aetiology, patho-physiology, sign and symptoms and available treatment options as per stage of disease and a gist of contemporary texts of Ayurveda related to Arsha (Haemorrhoid) have been documented to understand integrated and holistic treatment approach towards haemorrhoid management.

\section{Modern Perspective}

Definition of Haemorrhoid - Haemorrhoids, also called Piles are masses or clumps of tissues which consist of muscle and elastic fibres with enlarged, bulging blood vessels and surrounding supporting tissues present in the anal canal of an individual. It is a condition characterized by the prolapsed of an anal cushion that may result in bleeding and pain. ${ }^{[4]}$

Pathogenesis - The development of hemorrhoidal disease begins from dilatation within the cavernous bodies of the anal cushions primarily due to passing hard stool or straining at defecation, leading to, bruising of engorged venous cushions and rupture of artero-venous shunts resulting in bleeding (spontaneous or during defecation).

Etiology - The common etiological factors seen are- Congenital (by birth due to genetic defect), Anatomical (due to no firm support to GI track in pelvic floor), Sedentary lifestyle (Causing over filling of blood vessels), Alcohol (causing hepatitis leading to portal hypertension), Constipation, enlargement of Prostate, Asthma / Weight lifting (causing increase in intra abdominal pressure and over filling of blood vessels). Similarly, few distinct factors responsible in females are pregnancy, labour phase and uterine fibroids causing increase in intra abdominal pressure etc. 
Classification - Widely, hemorrhoids are classified into Internal (defect in internal hemorrhoidal plexus, located above the dentate line) and External hemorrhoids (defect in external hemorrhoidal plexus, located below the dentate). Further, Internal hemorrhoids are classified into four degrees. First degree hemorrhoids project into the canal and cause bleeding, but do not prolapse. Second degree hemorrhoids prolapse, but spontaneously reduce back into the canal. Third degree hemorrhoids must be reduced manually, and Fourth degree hemorrhoids are irreducible. Furthermore, on physical examination, they are typically located in the right anterior, right posterior, or left lateral position (3, 7, and 11 o' clock position).

\section{Clinical Manifestations}

External Hemorrhoids- Patients usually present with Peri-anal hematoma due to severe straining and per rectum bleeding due to rupture of dilated artero-venous shunts (anal cushion). It has sudden onset of painful lump / swelling at the anus, bluish in colour, covered with smooth shining skin, secondary thrombosis.

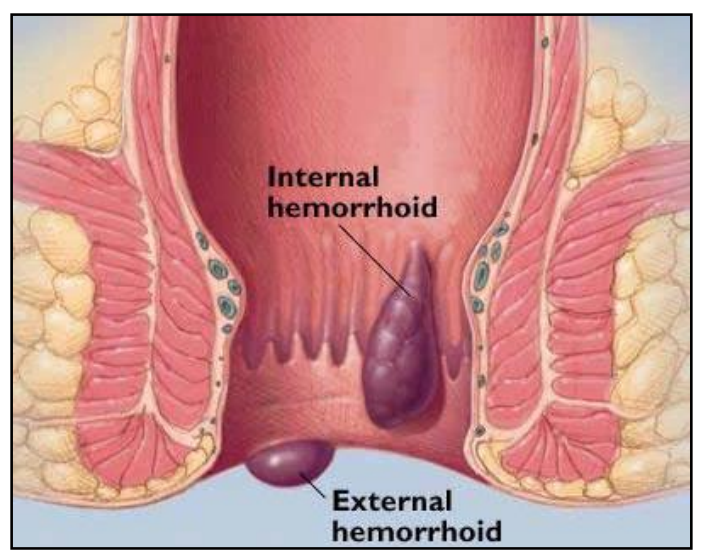

Internal Hemorrhoids- They are usually present with bleeding per rectum associated with defecation and a sense of fullness from prolapsed tissue, which may require manual reduction. Bleeding is spontaneous and painless (as they originate above dentate line).

Acute hemorrhoidal prolapse can be exquisitely tender, producing irreducible edematous tissue. Pressure necrosis, ulceration, and secondary infection can occur.

Differential Diagnosis- Differential diagnosis of Hemorrhoids includes painful bleeding from an anal fissure, full-thickness prolapse or procidentia, anal skin tags, thrombosed external hemorrhoids and $\mathrm{Ca}$-rectum (malignancy).

\section{Review on Treatment Alternatives}

External Hemorrhoids Management- In Acute stage (if patient comes within 48 hrs) with symptoms like severe pain with haematoma, then Analgesics, Anti inflammatory drugs are prescribed internally along with Xylocaine ointment for local application and hot water Seitz bath with $\mathrm{KMNO}_{4}$ is also advised. Similarly, Laxatives and Antibiotics can be prescribed adjuvantly. Further, if haematoma do not resolve, then it is incised under local anesthesia $\&$ the wound is allowed to heal by granulation tissue. If untreated, the haematoma undergoes either resolution or ulceration/suppuration to form an abscess/fibrosis which give rise to skin tag. 
Internal Hemorrhoids Management- Treatment for internal hemorrhoids depends on the severity of symptoms and response to conservative management. Moreover, various treatment alternatives practiced can be categorized as below-

1) Sclerotherapy - In sclerotherapy, sclerosing agents, such as polidocanol, quinine and urea or 5\% phenol in vegetable oil, are injected at the base of the haemorrhoid (into ano-rectal submucosa) above the dentate line. This decreases vascularity and increase fibrosis which fixes mucosa to muscle \& prevents prolapse. It is effective in $60-80 \%$ of first and second degree internal hemorrhoids; moreover, sclerotherapy is not as effective on large prolapsing hemorrhoids.

Rare complications include sloughing of the mucosa, reaction to the injection, and secondary infections.

2) Barron's Rubber Band Ligation- In this procedure, rubber ring ligature applied to the mucosal covered part of the internal pile through a proctoscope with the help of Barron's pile gun. Banding around the base of the hemorrhoid causes necrosis and sloughing, and subsequent ulceration and fibrosis of the mucosa fix the tissue to the underlying sphincter muscle, preventing sliding of the anal mucosa. It is effective in $65-75 \%$ of first and second degree internal hemorrhoids. Although less effective with third degree hemorrhoids, it can still be considered if one is attempting to avoid surgery. ${ }^{[5]}$

Common complications (less than $5 \%$ of patients) include bleeding, secondary infection, and pain if the band is placed too close to the dentate line.

3) Doppler Guided Hemorrhoid Artery Ligation (DGHAL)- DGHAL is performed using a modified proctoscope which is combined with a Doppler probe. This is inserted into the anal canal and used to identify the hemorrhoidal arteries. Sutures are then placed into the areas of arterial signal through an opening in the proctoscope. It performs both- legates the arterial supply of the hemorrhoids and pexies of the mucosa, reducing prolapse. ${ }^{[6]}$

Complication includes infection and hemorrhage, both with rates of less than $1 \%$. Recurrence rates also were not significantly different than those found with hemorrhoidectomy.

4) Infra-Red Coagulation- Infra-red photocoagulation transmits infrared radiation and coagulates the mucosa, with results similar to banding and sclerotherapy. It is applied to the apex of each hemorrhoid at top of anal canal, which coagulates tissue protein and dehydrates the cell. It causes actual burn upto the submucosa, causes tissue destruction \& evokes inflammatory reaction, ultimately results in scarring. If done properly, it also is relatively painless and complications are minimal.

5) Hemorrhoid Laser Procedure- In this, Hemorrhoidal arterial flow feeding the hemorrhoidal plexus is stopped by means of doppler-guided Laser coagulation. Though, very popular amongst patients, however practically, Laser photocoagulation offers no advantage over other treatment modalities as it is expensive and carries a greater risk of complications from unrecognized deep tissue destruction. ${ }^{[7,8]}$

6) Electrocoagulation- Electrocoagulation employs thermal injury to fibrose the hemorrhoidal tissue. Bipolar electrocautery employs similar instrumentation as the endoscopic devices and can be applied through an anoscope. Direct current electrotherapy 
requires more time and discomfort, but has shown better results in treating fourth degree hemorrhoids. A heater probe modified for use through an anoscope also shows good results with first and second degree hemorrhoids, but requires interval treatments.

7) Anal Dilation and Sphincterotomy - Reducing increased anal sphincter tone, and thus preventing engorgement of the vascular cushions, is the theory behind anal dilation and sphincterotomy. Manual dilation traumatically disrupts fibrotic bands and sphincter muscle fibers that contribute to increased anal tone. The complications from anal dilatation include mucosal tears, prolapse, and incontinence.

Similarly, surgical sphincterotomy also reduces high canal pressures, but is usually performed in conjunction with other procedures and is generally not performed as the sole treatment modality for haemorrhoids. The internal sphincter is partially divided under direct visualization, thus reducing anal pressure in a more controlled and predictable fashion than anal dilation.

8) Hemorrhoidectomy- Surgical haemorrhoidectomy is practiced in two ways - open and closed haemorrhoidectomy. In open haemorrhoidectomy, pile pedicle is transfixed and excised leaving raw wound surface, whereas in closed haemorrhoidectomy after excision of the pile mass, the wound surface is closed with the help of mucosal flap. Further, for better outcome, lateral sphincterotomy is practiced after surgical haemorrhoidectomy to relieve discomfort and post operative fissure formation. ${ }^{[9]}$

Haemorrhoidectomy is indicated for grade III and IV hemorrhoids and for patients with grade I and II haemorrhoids who have failed conservative management. One or all three haemorrhoidal complexes can be removed, under local/spinal anaesthesia. Hospitalization is required if procedure is done under spinal anaesthesia. The swelling and discomfort of surgical haemorrhoidectomy requires a longer recovery period (minimum of 2 weeks) but, with a recurrence rate less than $3 \%$, offers cure for most patients.

The common complications include bleeding, urinary retention, and abscess or fistula (less than $0.01 \%$ ), whereas rare complications includes sphincter damage, anal stenosis (less than $1 \%$ ) and loss of sensitivity.

Precautions- Hemorrhoidectomy should not be performed in the presence of local perianal inflammation or dermatitis. Patients with ulcerative colitis should be treated only while in remission. Caution should be exercised for patients with Crohn's disease as well; if the patient has active anorectal Crohn's disease, then hemorrhoidectomy wounds may not heal. Hemorrhoidal flare-ups during pregnancy can be treated conservatively in most instances; however, grade IV disease can be surgically treated during all three trimesters with acceptable results. Patients with AIDS and Viral Hepatitis may safely undergo hemorrhoidectomy, provided their immune status is stable.

9) Stapled Hemorrhoidopexy- This is also known as Stapled Anupexis (Longo technique) or MIPH i.e. minimally invassive procedure for hemorroids. It is highly effective in Grade III- IV haemorrhoids specially with mucosal prolapse. Stapled hemorrhoidopexy is performed using a circular stapling device which is inserted into the anal canal. A purse string suture is then placed into the mucosa, approximately $2 \mathrm{~cm}$ above the superior aspect of the hemorrhoids. The opened stapler device is inserted into the purse string suture, which is then tightened. Next, the stapler device is closed and fired, thereby excising a ring of hemorrhoidal tissue. The results of this mucosectomy are thought to be twofold, both reducing the prolapsed anal mucosa and disrupting the vascular supply to the hemorrhoids. [10,11] 


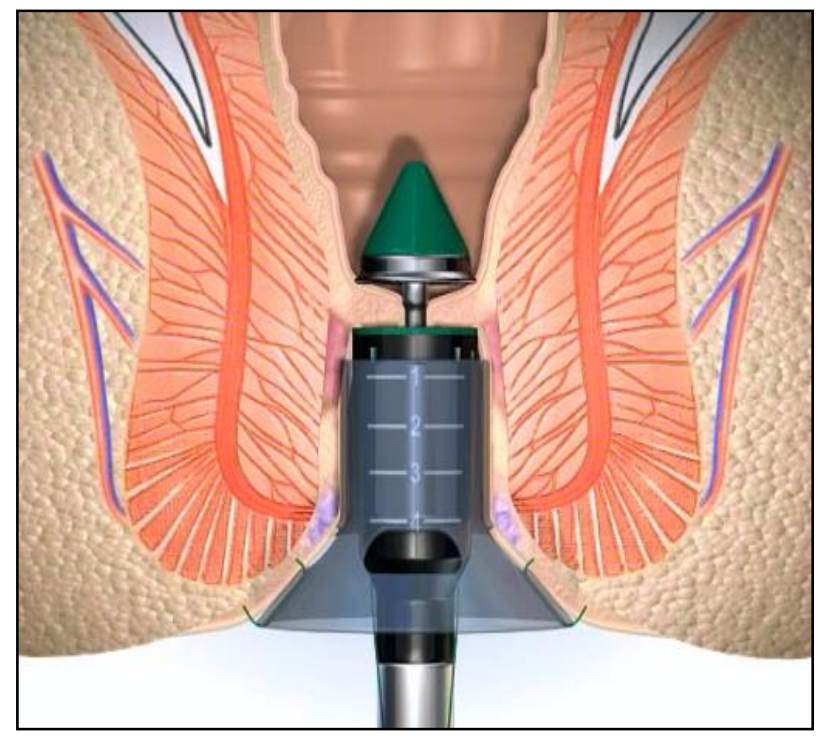

This procedure, when compared to the conventional excisional haemorrhoidectomy, is found to cause less postoperative pain and fewer complications from bleeding with comparable recurrence rates. However, it is not devoid of moderate complications rate such as technique associated risks like post-op. bleeding, perforation and sphincter lesions. ${ }^{[12]}$

\section{Ayurvedic Perspective}

Hemorrhoids can be co -related with Arsha or Gudarsh mentioned in Ayurvedic texts. Further, Arsha is included in Ashta-mahagada category (amongst 8 diseases which are difficult to treat). Arsha is defined as a disease which produces extreme discomfort to the patient resembling one's enemy, leading to painful defecation and pile mass formation.

Pathogenesis (Samprapti) - If a non- self possessed person continuously practices un salutary lifestyle and food habits, particularly indulge in strenuous work-exercise, deliberately holding natural urges or consume incompatible meals, which leads to vitiation of Vata dosh and derangement of digestive fire (jattharagni). This vitiated Vata, further vitiates blood and muscle tissue (Rakta, Maans dhatu) and local blood vessels (pradhan dhamani), travels downwards, and affect sphincters and surrounding anatomical structures in the anal canal, leading to pile mass formation i.e. hemorrhoids (Gud Arsha). ${ }^{[13]}$

Types (Arsha Prakar) - Sushrut has described 6 types of Gud Arsha such as - Vataj, Pittaj, Kaphaj, Sannipataj, Raktaj and Sahaj (Congenital). Further, as per clinical manifestation, Arsha is classified into Shushkarsha (Dry or non bleeding hemorrhoids) and Raktarsha (Bleeding hemorrhoids).

Symptoms (Lakshan) - Primary symptoms are bleeding per rectum, mass like protrusion coming out from anal canal, painful defecation and itching at anal region, whereas, associated prodromal features are - Ajeerna (indigestion), Agnimandya (low digestive fire), Malavrodha (obstructive syndrome/constipation), Gudparikartan (anal fissure), Gudabhransha (rectal prolapse), Grahani (irritable bowel syndrome) and Yakrut vikar (deranged liver functioning due to hepatitis, portal hypertension) etc. 


\section{Ayurvedic Management of Arsha}

Sushruta has advocated fourfold therapy for Arsha such as -

1) Bheshaja/Aushadhi chikitsa (Medicinal treatment): Bheshaja chikitsa is advocated when symptoms are mild \& less complicated with onset less than 1 year \& with less vitiated Doshas. The basic conservative Ayurvedic management is primarily aimed at Agni Deepan- Pachan (improving digestion), Vata Anuloman (pacifying bowel movements), Rakta shodhan (blood purifier) - stambhan Chikitsa (Hemostatic medicines) and MalSarak Chikitsa (Laxatives).

The line of treatment can be prescribed as below-

\section{Internal Medicines for Dry Piles - (Shushka Arsha)}

1) Kankayan Guti + Triphala Guggulu + Arogyavardhini vati - Each 2 Tab. 3 times a day with lukewarm water after meals.

2) Abhayarishtha - 4 tablespoon with equal amount of water 2 times after meals.

3) Amrutbhallatak Awleha - 1 tablespoon each morning with luke warm water.

4) Gandharva Haritaki Churna - 1 tablespoon at bed time with warm water.

(*Ajmodadi Churna, Avipattikar Churna, Samasharkara Churna, panchsakar churna or Triphala churna, Takrarishatam can be added / replaced as per availability and requirement)

\section{Local application in Dry Piles -(Shushka Arsha)}

Arshoghn Lep- (Topical Application to promote fibrosis and delay the protrusion)

Such as Snuhi Latex+Haridra, Haridra+Pippali+Gomutra, Nimbadi Malhar etc.

Apply Sarjarasa malhar or Shatadhaut ghruta locally (anal canal)

Fumigate with Guggulu, Vacha, Dhoopa, Ajmoda etc. (Sthanik Dhupan)

Apply Chukra, Kashisadi or Pippalyadi Tail and advice Seitz bath.

\section{Internal medicines for Bleeding Piles- (Rakta Arsha)}

1) Praval pishti + Kamaduha ras + Bolbaddha ras - 2 Tab. 3 times a day with water before meals (given when Pitta dosha is aggravated leading to bleeding piles ).

2) Kutajarishta+ Ashokarishta - 30ml each with equal amount of water, twice after meals (if Piles due to IBS).

3) Nagkeshar +Lodhra Churna - 500mg each with butter \& warm water 3 times a day.

4) If severe weakness due to bleeding - Mauktik Bhasma $50 \mathrm{mg}+$ Nagkeshar churna $500 \mathrm{mg}$ + Tapyadi loha vati 2-tab BD -with Lohasav 40ml mixed with equal quantity of water twice a day (as hemostatic and to improve haemoglobin due to blood loss).

Kshar karma (Application of Alkaline paste): Kshar karma i.e. application of 'Pratisaraneeya Kshar' (alkaline-caustic paste) on the pile pedicle is mentioned in Sushrut samhita. This is indicated in Grade II / III non- bleeding internal haemorrhoids where pedicle is Mridu (soft), Prasrut (Extenssive), Avagaadh (Deep seated-internal?) \& Uchhrita (Projecting).

The Kshar paste is applied to the dilated pile pedicles with the help of probe under the guidance of specially designed 'ArshoDarshan Yantra' resembling slit- proctoscope. After Kshar 
application the pile pedicle is washed with Dhanyaamla (sour gruel which neutralises the chemical reaction) and followed by local application of Yashtimadu Ghrita. ${ }^{[14]}$

It is hypothesized that, Kshar karma causes protein coagulation and necrosis of the tissues which slough outs the pile mass. Some Ayurvedic surgeons prepare a distinct Kshar sutra which is mild in nature (Coated only with Snuhi latex + Haridra powder, without use of Kshar) and having fewer coatings as well, for the ligation of pile pedicle. Moreover, this Kshar sutra is different than conventional Apamarg Kshar sutra used in Bhagandar (fistuala-in ano) management.

Agni karma (Heat Burn Therapy): This is indicated when pile pedicle is Karkash (Rough), Sthir (Firm), Prithu (Thick) \& Katthin (Hard- fibrosed). Though, there are only anecdotal reports available on role and use of conventional Agnikarma in Arsha chikitsa, however, we can definitely co-relate this with IRC, Electro-coagulation and advanced Laser Techniques used for Grade II \& III hemorrhoid ablation, in which various heat sources are used to perform thermal/ heat burn. Similarly, Excision of external sentinel tags with the help of thermal cauterization seen in chronic fissure can also be considered as Agnikarma chikitsa.

Shalya karma (Excision of Pile mass): Shalya karma i.e. excision of piles is indicated when pile mass is of Tanu Mool (Narrow Base), Uchhrita (Projecting/Prolapsed) \& Kled yukta (Discharging/Bleeding) resembling III grade \& IV prolapsed hemorrhoids.

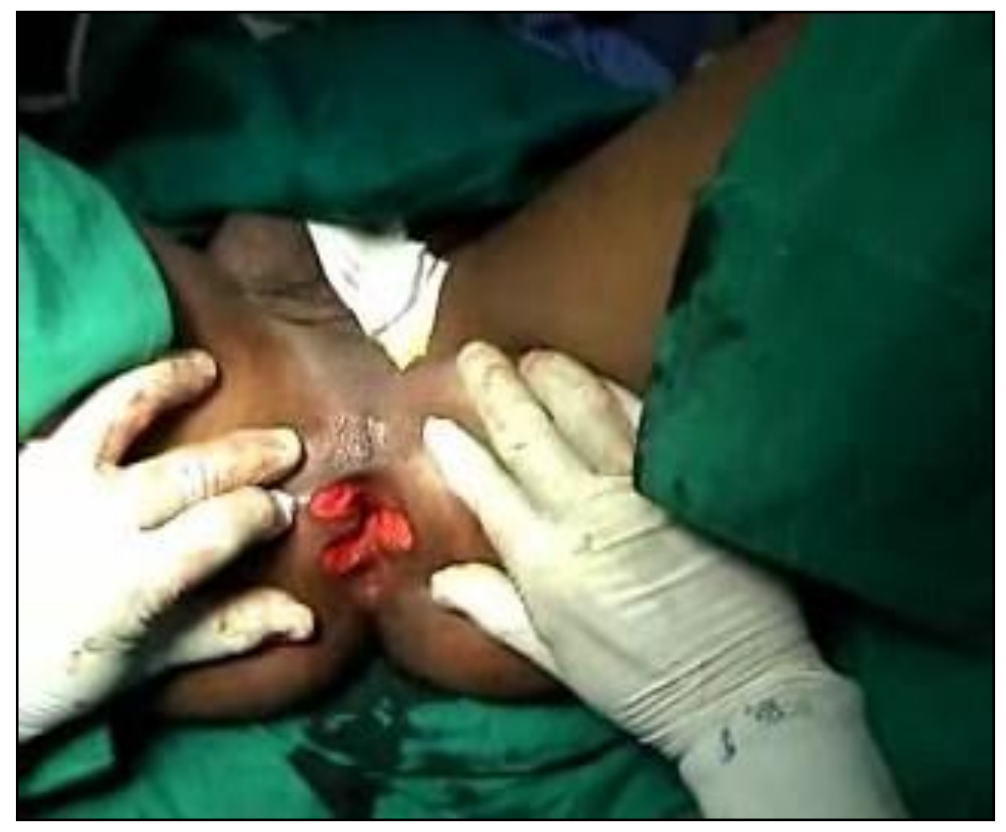

Shalyakarma or Arsha Chhedan karma is very much similar to conventional surgical haemorrhoidectomy, in which firstly, each pile pedicle is ligated /transfixed separately with the help of thread followed by excision of pile mass (prolapsed anal cushion). The procedure leaves discomfort and pain at operative site due a raw wound left after excision, which heals in due course of time. In spite of all the advancement in the field of surgery, conventional hemorrhoidectomy is believed to be the gold standard of hemorrhoid treatment, due to safe, cost effective and less recurrence rate. 


\section{Dietary Regimen}

1) Gruel mixed with Ghrit or Milk, Shatavari mula kalka with milk, Apamarga mula cooked with rice ,Butter milk, Jaggery with Haritaki

2) Use of Suran (only for Dry piles) and Takra (butter milk) is advisable.

3) If excessive bleeding, instead of Suran, take black resins 30 to 40 each day.

4) Old rice, wheat, Takra, Shunth (dry ginger powder), Padaval (snake gourd) etc. is good for piles.

5) If Agnimandya (low digestive fire) and Pitta prakop (Vitiated Pitta) condition, then one should avoid Dairy products such as Yoghurt, Cheese, Paneer, Maida (white flour) and its products, mature Reddish, Carrot and Cucumber etc. as they are heavy to digest.

6) To pacify aggravated Pitta, Shatavari powder, Sariva powder can be opted in water or in milk

7) Drinking water with roots of Ushir helps pacify Pitta-Rakta to much greater extent. Similarly, Garcinia drink (Kokum), Amalaki juice is also advocated.

8) Fruits like Papaya and other sour tasting fruits except for Lemon to be avoided.

9) Also, certain un salutary life style such as Sitting on uneven- hard surface, or in the same position for long, riding a bike, travelling, keeping late at night, alcohol ,tobacco, smoking, forcible bowel movements should be avoided and local ano-rectal hygiene to be maintained.

\section{Result/ Inference-}

Several procedures have been developed to fibrose the haemorrhoid tissue onto the underlying internal sphincter, thus restoring support for these vascular cushions and thereby preventing prolapse. The therapeutic assessment and validation of various ttreatment alternatives can be summarized as below-

Dietary and lifestyle modification is desired in all stages of haemorrhoids ranging from Grade I to Grade IV.

Office procedures such as Rubber band ligation, Sclerotherapy, Infrared coagulation, DGHL etc are effective in Grade I - II and early Grade III haemorrhoids.

Operating-room procedures such as Hemorrhoidectomy and Stapled hemorrhoidopexy are advocated in Grade Grade III \& IV haemorrhoids.

Similarly, assessment of Ayurvedic treatment modalities reveals, Bheshaja, Kshar karma and Agni karma effective in the Grade I \& II Arsha (hemorrhoids) whereas, Shalya karma for Grade III \& IV hemorrhoids management.

When dietary and lifestyle modifications fail to reduce symptoms, sclerotherapy, rubber band ligation, and coagulation techniques may avoid surgical hemorrhoidectomy in up to $80 \%$ of patients with first and second degree internal haemorrhoids.

\section{Discussion and Conclusions}

Haemorrhoid even if appears to be a local disease but is the manifestation of deranged gastrointestinal system, weak or low digestive fire (mandagni) leading to malformation or ill formed stools. This ill formed stools are very difficult to excrete by the body hence, is followed by straining unconsciously by the patient. Ayurveda is the science which deals with this route cause of the disease of vitiated Agni and digestion of stools. Accordingly, deepan dravya followed by pachan dravya helps in increasing digestive fire and facilitates digestion. Anuloman dravya deals 
with digestion of stools and then expelling them example being Haritaki. Moreover, as per severity of symptoms of constipation, Sharangdhar samhita explains further treatment modalities of expelling of stools like - Sansran, Bhedan, Rechan which should be adopted by the practitioners as per the body constitution (prakruti) and disease manifestation.

Haemorrhoid due to Ulcerative colitis, Irritable Bowel Syndrom, Crone's disease fall under treatment of Grahani and Atisar in Ayurveda and calls for a separate research paper due to vastness of subject. Haemorrhoid due to Alcoholic Liver Disease, Portal Hypertension, Ascites is again a symptom due to these diseases and not be seen as a different disease hence, are not incorporated in this present article.

Further, treatment for hemorrhoids ranges from dietary and lifestyle changes to surgical excision, and depends on the severity of symptoms and response to conservative management. Hence, the management can be classified into 3 categories:

Diet and lifestyle modification- For mild to moderate symptoms, a high-fiber diet and bulk dietary supplements can help alleviate pressure and bleeding. Patients should be encouraged to drink water and defecate without delay at the urge sensation. It is useful in all patients with grade I or II Hemorrhoids.

Non operative / office procedures- Several procedures have been developed to fibrose the hemorrhoidal tissue onto the underlying internal sphincter, thus restoring support for these vascular cushions and thereby preventing prolapse. When dietary and lifestyle modifications fail to reduce symptoms in all patients with grade I or II and most patients with -grade III, Sclerotherapy, Rubber band ligation, and Coagulation techniques may avoid surgical hemorrhoidectomy in up to $80 \%$ of patients with first and second degree internal hemorrhoids.

Operative procedures- Surgical hemorrhoidectomy is indicated for grade III and IV hemorrhoids and for patients with grade I and II hemorrhoids who have failed conservative management.

Topical preparations that contain a combination of local anaesthetics, corticosteroids, astringents, and antiseptics are available, and these can alleviate symptoms of pruritus and discomfort in haemorrhoidal disease. Long term use of these agents should be discouraged, particularly steroid creams, which can permanently damage or cause ulceration of the peri anal skin.

Ayurvedic management- Sushruta has advocated fourfold therapy for Arsha such as Bheshaja/Aushadhi chikitsa (Medicinal treatment), Kshar karma (Application of Alkaline paste), Agni karma (Heat Burn Therapy) and Shalya karma (Excision of Pile mass) based on stage of Arsha. Further, Bheshaja, Kshar karma and Agni karma is effective in Grade I \& II hemorrhoids whereas, Shalya karma is practiced in Grade III \& IV hemorrhoids. ${ }^{[15]}$

This article attempts to simplify haemorrhoid management and touches maximum aspects of this common ano rectal problem with an integrated and holistic approach. Hope the article will prove useful to practitioners and students/researchers who wish to know about authentic haemorrhoid management. 


\section{References}

[1] John Goligher, Author (Fifth edition), Surgery of Anus Rectum \& Colon, Vol. 1, Chapter 4, A.I.T.B.S. Publishers, Delhi-India: 2004; P 99-106.

[2] Vaidya Priyavrat Sharma, Editor (Reprint edition), English translation of text and Dalhan commentary (Vol.2) on Sushrut Samhita of Sushruta, Nidan sthan, Chapter 2, verse 4, Varanasi, Chaukhamba vishwabharati : 2010, P 19.

[3] Vaidya Priyavrat Sharma, Editor (Reprint edition), English translation of text and Dalhan commentary (Vol.2) on Sushrut Samhita of Sushruta, Chikitsa sthan,Chapter 6, verse 4, Varanasi, Chaukhamba vishwabharati : 2010, P 225.

[4] https://www.glowm.com/section_view/heading/Common\%20Anorectal\%20Problems/item/71 (last accessed on 23/4/2019).

[5] MacRae HM, MacLeod RS: Comparison of hemorrhoidal treatment modalities. A meta-analysis. Dis Colon Rectum,1995;38: 687.

[6] Sohn N. Aronoff JS. Cohen FS. Weinstein MA: Transanal hemorrhoidal dearterialization is an alternative to operative hemorrhoidectomy. Am J Surg, 2001; 182(5): 515-19.

[7] Endres JC, Steinhagen RM: Lasers in anorectal surgery. Surg Clin North Am, 1994; 74: 1415.

[8] Randall GM, et al: Prospective randomized comparative study of bipolar versus direct current electrocoagulation for treatment of bleeding internal hemorrhoids. Gastrointest Endosc, 1994; 40: 403.

[9] Mazier WP: Hemorrhoids, fissures and pruritus ani. Surg Clin North Am, 1994; 74: 1277.

[10] Hard A. Chan CLH. Cohen CRG: The Surgical Management of Hemorrhoids - A Review. Dig Surg, 2005; 22: 26-33.

[11] Gravié JF, Lehur PA, Huten N, et al: Stapled hemorrhoidopexy versus Milligan-Morgan hemorrhoidectomy: a prospective, randomized, multicenter trial with 2-year postoperative follow up. Ann Surg, 2005; 242: 29-35

[12] Sutherland LM, Burchard AK, Matsuda J, et al: A systematic review of stapled hemorrhoidectomy. Arch Surg, 2002; 137:1395-1406

[13] Vaidya Priyavrat Sharma, Editor (Reprint edition), English translation of text and Dalhan commentary (Vol.2) on Sushrut Samhita of Sushruta, Nidan sthan, Chapter 2, verse 4, Varanasi, Chaukhamba vishwabharati : 2010, P 19.

[14] Prof.K.R.Srikantha Murthy, Editor (Fifth Edition), English translation of Astang Sangrah of Vagbhata, Chikitsa sthan, Chapter 10, verse 2-4, Varanasi, Chaukhamba Orientalia: 2005, P 378379

[15] Vaidya Priyavrat Sharma, Editor (Reprint edition), English translation of text and Dalhan commentary (Vol.2) on Sushrut Samhita of Sushruta, Chikitsa sthan, Chapter 6. Verse 4-6, Varanasi, Chaukhamba vishwabharati : 2010, P 328-329.

\footnotetext{
*Corresponding author.

E-mail address: amar.dwivedi @dvnatil.edı
} 